\title{
A Case of Three-Stage Treatment of Bilateral Synchronous Renal Carcinoma with Metastatic Brain Lesions
}

DOI: $10.17691 / \mathrm{stm} 2015.7 .3 .23$

Received February 02, 2015

P.S. Zubeev, MD, DSc, Professor, Head of the Department of Extreme Surgery, Faculty of Doctors' Advanced Training';

Chief Doctor?

O.A. Korovin, Head of Urology Department ${ }^{2}$;

F.A. Sevryukov, MD, DSc, Professor, the Urology Department named after E.V. Shakhov ${ }^{1}$

INizhny Novgorod State Medical Academy, 10/1 Minin and Pozharsky Square, Nizhny Novgorod, 603005,

Russian Federation:

${ }^{2}$ City Hospital No.33, 54 Prospect Lenina, Nizhny Novgorod, 603076, Russian Federation

There has been described a case of surgical management of bilateral synchronous renal carcinoma with metastatic brain lesions. The feature of the observation is tree-stage treatment: the initial resection of the secondary brain lesion followed by the left nephrectomy 14 days later and the right nephrectomy a month later. $40 \%$ right kidney was preserved. The patient required no substitution therapy in the postoperative period.

Key words: synchronous renal carcinoma; partial nephrectomy; renal cell carcinoma; contrast enhanced magnetic resonance imaging.

Nowadays, kidney tumors occupy one of the leading positions in urologic cancer. According to the statistical data, about $95 \%$ of kidney tumors are malignant, which compels doctors to use surgical methods of treatment. It is worth mentioning that bilateral renal carcinoma occurs more and more often. The management of this pathology is always individual: it is required to remove the tumor radically with maximum preservation of intact kidney tissue. Here is presented a specific case of synchronous renal carcinoma with metastatic brain lesions and a three-stage cancer treatment.

Informed consent to use the data was received from the patient.

Patient K., aged 69, complaining of vomiting, weight loss, and urine color change (hematuria) was urgently hospitalized to City Hospital No.33 of Nizhny Novgorod on 24.03.2014. The symptoms were lasting for the last 6 days. The patient sought no medical aid. He had not undergone abdominal ultrasound examination for the last 5 years.

According to the hospital ultrasound findings, the left kidney was $19 \times 7 \times 5 \mathrm{~cm}$, the parenchyma was up to $2.0 \mathrm{~cm}$, in the upper pole area with transition to the middle segment there was a cystic-solid mass lesion $10 \times 9 \mathrm{~cm}$ with the signs of blood flow, the pyelocaliceal system (PCS) deformity was also observed. The right kidney was $12 \times 6 \times 4.5 \mathrm{~cm}$, the PCS was normal, parenchyma thickness amounted to $2.3 \mathrm{~cm}$, there was a mass lesion $6 \times 5 \mathrm{~cm}$ in the upper pole projection.

According to excretory urography findings, there were no concrement shadows, the left kidney function was reduced, the PCS contrasting occurred on the $30^{\text {th }}$ minute,
PCS deformity was present, the upper and middle calix groups were distorted due to the mass lesion, the ureter was contrasted up to the urinal bladder. The right kidney function was satisfactory, the PCS showed no dilatation, the ureter was visualized along the whole length.

MRT findings of the retroperitoneal space dated 26.03 (Figure 1): the left kidney size $188 \times 87 \times 69 \mathrm{~mm}$, distorted, the outer contours tuberous due to the lesions of inhomogeneous structure, consisting of solid, pseudoparenchymatous and cystic components occupying its upper and middle segments; the right kidney size $125 \times 68 \times 57 \mathrm{~mm}$, in the upper pole - a tumor-like mass distorting the upper-medial kidney boundary, $65 \times 47 \times 40 \mathrm{~mm}$ in size, inhomogeneous in structure and cystic-solid in character. No enlargement of regional lymphatic nodes is revealed. The mass lesions accumulate contrast material.

Symptomatic therapy was started to the patient. In the course of treatment there was observed dyspepsia in a form of vomiting 5-6 times a day, which was impossible to stop.

Brain MRT findings dated 27.03 (Figure 2): the evidence of a mass lesion $3.5 \times 3.0 \mathrm{~cm}$ in the projection of cerebellum.

According to the data obtained from abdominal ultrasound examination and chest radiography, no secondary foci were revealed.

Basic diagnosis: "synchronous renal carcinoma $T_{2} N_{x} M_{1}$ (with metastatic brain lesions), stage IV".

Concomitant diagnosis: "atherosclerotic cardiosclerosis, recurrent ventricular tachycardia, congestive heart failure, stage IIA, functional class III (NYHA)".

The council of physicians was gathered which decided to transfer the patient to the neurosurgical department of

For contacts: Korovin Oleg Aleksandrovitch, e-mail: dok.kor1177@mail.ru 


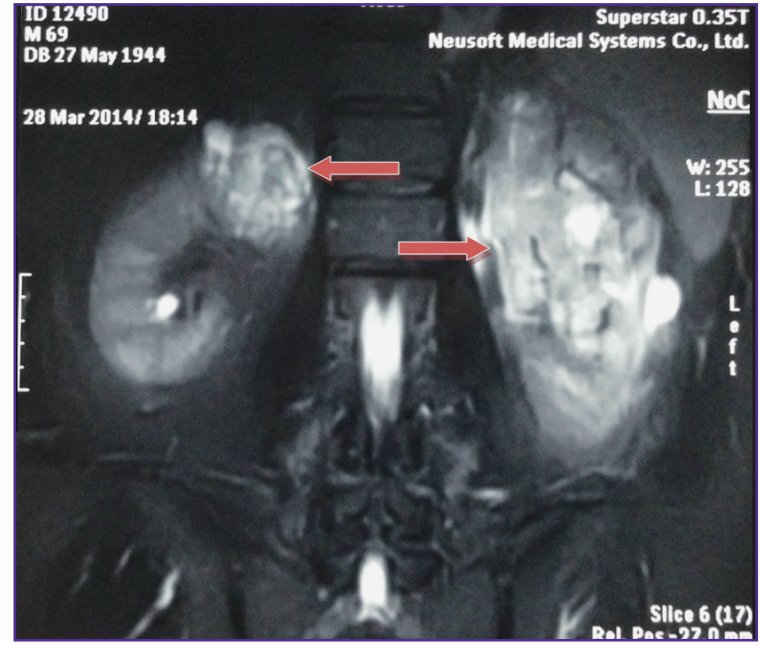

Figure 1. Contrast-enhanced magnetic resonance tomogram: the left kidney tumor $-10 \times 9 \mathrm{~cm}$, the right kidney upper pole tumor $-6.5 \times 4.5 \mathrm{~cm}$

City Hospital No.39. After premedication, on 8.04.2014 the patient underwent craniotomy of the postcranial fossa and tumor removal. The post-operative period was normal, the wound healing with primary adhesion. All dyspeptic disorders were noted to discontinue.

Histology findings dated 16.04: metastasis of renal cell carcinoma.

On 15.04 the patient was discharged and readmitted to City Hospital No.33 for a planned surgical treatment on 25.04. After preoperative preparation the council of physicians made a decision to perform left-side nephrectomy.

Complete blood count: $\mathrm{Hb}-135 \mathrm{~g} / \mathrm{L} ; \mathrm{WBC}-4.4 \cdot 10^{9}$; ESR - $23 \mathrm{mmol} / \mathrm{L}$. Blood biochemistry: urea $-5.3 \mathrm{mmol} / \mathrm{L}$; creatinine - $85 \mathrm{mmol} / \mathrm{L}$; sugar - $4.7 \mathrm{mmol} / \mathrm{L}$. Diuresis $1,500 \mathrm{ml}$.

On 29.04 the patient was operated on: laparotomy, left-side nephradrenalectomy, para-aortic lymph node dissection were carried out.

Complete blood count dated 7.05: $\mathrm{Hb}-108 \mathrm{~g} / \mathrm{L}$; WBC $-9-8 \cdot 10^{9}$.

Blood biochemistry: urea - $6.0 \mathrm{mmol} / \mathrm{L}$; creatinine $114 \mathrm{mmol} / \mathrm{L}$.

The post-operative period was normal. Diuresis $1,700 \mathrm{ml}$.

Histology findings dated 8.05: a macrokidney with a paranephric body $19 \times 8 \times 10 \mathrm{~cm}$ in size. A tumor $9 \times 8 \times 7 \mathrm{~cm}$, dirty yellow in color, replacing kidney tissue in the area of the pelvis and the upper pole was seen on the sectioned sample. Penetration to the adjacent paranephric body was visible. On the kidney surface there was a cyst $6 \times 6 \mathrm{~cm}$ not connected with the tumor. Contiguous to the upper kidney pole was the adrenal gland $4 \times 3 \mathrm{~cm}$, unattached to it there was a para-aortic cellular tissue of a dirty yellow color (18 pieces). Histopathology report: renal cell carcinoma, clearcelled type with the foci of granular-cell structure G2, with invasion through the renal capsule, hemorrhages and

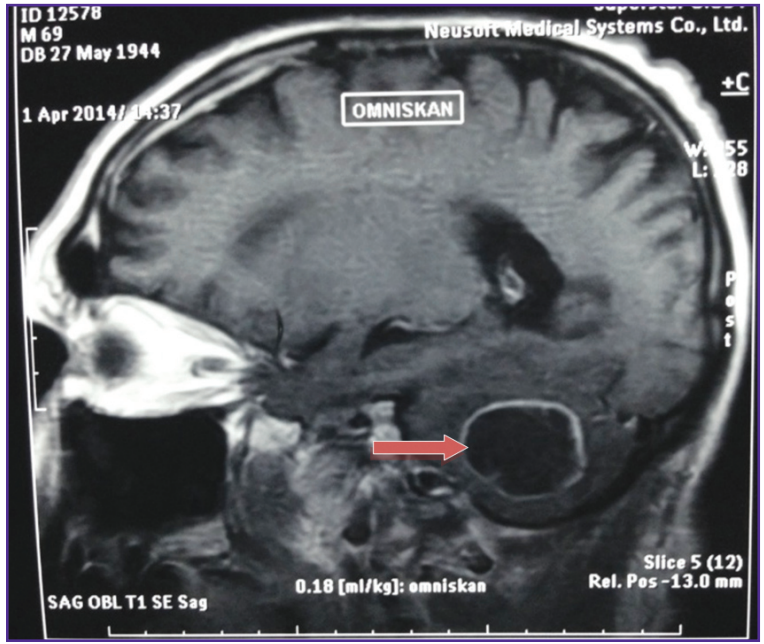

Figure 2. Magnetic resonance tomogram of the brain, sagittal scan: a metastatic focus in the brain

necroses; retention cyst; no tumor growth revealed in the adrenal gland and lymphatic tissue.

The post-operative wound healed with primary adhesion. The stitches were removed on day 10. The patient was discharged from the hospital on day 12 after the surgery.

On 10.06 the patient was repeatedly taken to hospital for a planned surgical treatment.

Ultrasound examination findings dated 10.06: a single right kidney had a mass lesion $6 \times 5 \mathrm{~cm}$ in the upper pole projection, the adrenal gland was not visualized.

Blood biochemistry: urea - $7.5 \mathrm{mmol} / \mathrm{L}$; creatinine $108 \mathrm{mmol} / \mathrm{L}$.

Excretory urography findings: kidney function was satisfactory, the PCS showed no dilatation, the ureter contrasted along the entire length. Taking into account the location of the tumor, a decision to determine the epinephrine level (aldosterone, cortisol, adrenaline) was made.

The council of physicians informed the patient about the possibility of administering a life-long replacement therapy (hemodialysis) in the post-operative period, if the symptoms of chronic renal insufficiency aggravated, as well as about the possibility of the right kidney nephrectomy after intraoperative visualization of the tumor and assessment of its operability. Consent to carry out surgical treatment was received from the patient.

On 12.06 the surgery was performed: right lumbotomy, the right kidney upper pole resection, retroperitoneum draining. Intraoperatively, the upper pole tumor was revealed, located intra- and extrarenally, $6 \times 5 \mathrm{~cm}$ in size, gray-yellow in color; the adrenal gland was mobilized off the kidney, not fused with the tumor. DeBaky forceps were applied on the kidney vessels (the artery, the vein). Thermal ischemia lasted $9 \mathrm{~min}$. Segmental resection was performed $1.5 \mathrm{~cm}$ away from the tumor. A neoplasm $0.8 \times 0.9 \mathrm{~mm}$ was found in the lower pole and was removed 5-7 $\mathrm{mm}$ away from the tumor. The kidney wound was sutured with quilting 


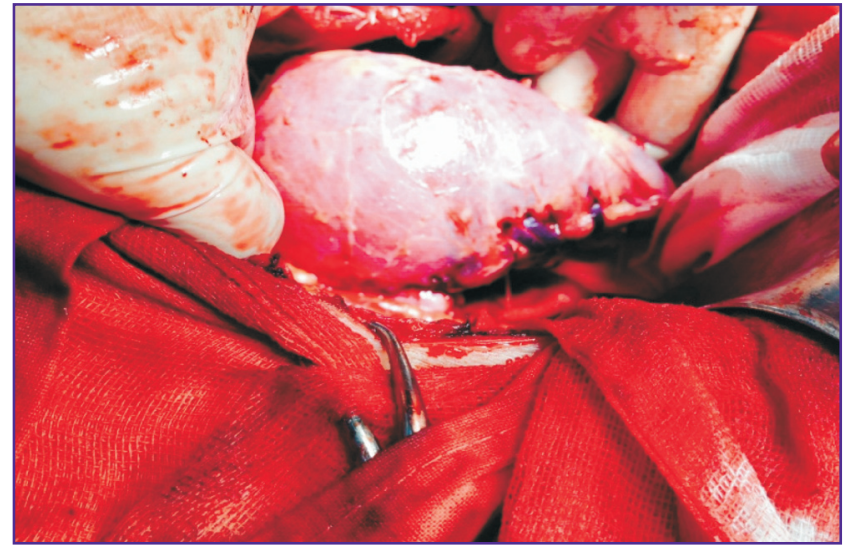

Figure 3. The right kidney after segmental resection

and simple uninterrupted stiches, dissected calices were sutured with atraumatic material (monocin 2.0), blood loss equaled $150 \mathrm{ml}$. Absorbing drainage was removed on day 3-4 (Figure 3).

The patient spent 5 days in the resuscitation and intensive care department. On the first day after the surgery diuresis was $200 \mathrm{ml}$. Blood biochemistry: urea - $16.3 \mathrm{mmol} / \mathrm{L}$; creatinine $-252.8 \mathrm{mmol} / \mathrm{L}$. Antibiotic and infusion therapies were carried out as well as thromboembolic complication prophylaxis.

14.06: diuresis was $300 \mathrm{ml}$; urea - $22.4 \mathrm{mmol} / \mathrm{L}$; creatinine - $380 \mathrm{mmol} / \mathrm{L}$; blood electrolytes: PO2 $33.7 \mathrm{~mm} \mathrm{Hg}, \mathrm{PCO} 2-28.4 \mathrm{~mm} \mathrm{Hg}, \mathrm{pH}-7.308(-), \mathrm{Na}-$ $131.8 \mathrm{mmol} / \mathrm{L}, \mathrm{Ca}-0.168 \mathrm{mmol} / \mathrm{L}, \mathrm{K}-2.66 \mathrm{mmol} / \mathrm{L}$. The patient was awake, extubated, his condition being critical but stable. Repeated analyses: diuresis - $500 \mathrm{ml}$; urea $23.0 \mathrm{mmol} / \mathrm{L}$; creatinine - $437 \mathrm{mmol} / \mathrm{L}$. The patient was consulted by a nephrologist, head of the out-patient dialysis department. The decision to continue symptomatic therapy was taken. There were no indications for replacement therapy.

On 15.06 diuresis was $3,500 \mathrm{ml}$, the patient was stable, transferred to urology department where conservative therapy went on. On day 10 after the surgery blood indices were the following: urea - $12.4 \mathrm{mmol} / \mathrm{L}$; creatinine $261 \mathrm{mmol} / \mathrm{L}$. Average diuresis per day was 1,200$1,800 \mathrm{ml}$.

Histology dated 18.06, macroscopic: three samples of adipose tissue were without indurations: the lesser $2.7 \times 2.0 \times 2.1 \mathrm{~cm}$, larger $-5.0 \times 3.0 \times 2.0 \mathrm{~cm}$; part of the kidney $8.0 \times 6.0 \times 6.0 \mathrm{~cm}$ in size had a perinephric cellular tissue, a mottled - type mass lesion $7.3 \times 5.8 \times 5 \mathrm{~cm}$ with the areas of brown and yellow color and in some places of colloidal-type, visible on the section; the tissue fragment was $1.0 \times 1.0 \times 0.7 \mathrm{~cm}$ in size, of soft consistency, dirty gray on the histological section, of homogeneous type. Histopathology report: adipose tissue with occasional petechial hemorrhages. Renal cell carcinoma, clear-celled type G2, without invasion through the renal capsule, with multiple hemorrhages and necroses. The stitches were removed on day 9-10. The post-operative wound healed with primary adhesion.

Final diagnosis: "synchronous renal carcinoma $p T_{2} N_{0} M_{1}$ (with metastatic brain lesions), G2, stage IV. The condition after removal of the secondary focus in the brain, left nephrectomy, right kidney resection". The patient was transferred to the nephrology department for follow-up treatment.

Six months after the operation the patient was examined for the first time. The patient's condition was satisfactory. Diuresis per day was 1,200-1,500 ml, the appetite was good, no edema, AP was 140/170 mm Hg. Blood biochemistry: urea - $10.4 \mathrm{mmol} / \mathrm{L}$; creatinine - $206 \mathrm{mmol} / \mathrm{L}$. According to the ultrasound and MRT findings, the right kidney was $7 \times 4 \mathrm{~cm}$, the parenchyma was $1.8 \mathrm{~cm}$, the PCS was not dilated. There were no recurrence signs revealed in the left renal bed. No enlargement of the retroperitoneal lymphatic glands was found.

It is the bilateral renal damage that makes our case report so specific. The surgical management in this pathology is always individual. One-stage removal of the tumors in both kidneys is quite traumatic and the post-operative period runs more severely. The present example proves that it is necessary to aim at the maximum preservation of the solitary kidney tissue regardless of the tumor size in order to spare the patient replacement treatment thus providing him with a satisfactory life quality.

Study Funding. This study was not supported by any financial sources.

Conflicts of Interest. The authors have no conflict of interests to disclose. 